\title{
EFEITO DA TEMPERATURA NA AVALIAÇÃO DA QUALIDADE FISIOLÓGICA DE SEMENTES DO MARACUJÁ-DOCE (Passiflora alata Dryander) ${ }^{1}$
}

\author{
ELISETE APARECIDA FERNANDES OSIPI ${ }^{2} \&$ JOÃO NAKAGAWA ${ }^{3}$
}

\begin{abstract}
RESUMO - Com o objetivo de verificar condições favoráveis de temperatura para a germinação das sementes do maracujá-doce (Passiflora alata Dryander), utilizou-se como tratamento de cinco plantas fornecedoras de sementes e duas temperaturas de germinação, na ausência de luz: $25^{\circ} \mathrm{C}$ constante e $20-30^{\circ} \mathrm{C}$ alternada. Os arilos das sementes provenientes de frutos maduros, completamente amarelos, foram extraídos com a utilização de liquidificador em baixa rotação. As características avaliadas nas sementes foram: peso, conteúdo de matéria seca, teor de água, porcentagem de germinação (plântulas normais), de plântulas anormais, de sementes dormentes e mortas. Concluiu-se que a temperatura alternada $20-30^{\circ} \mathrm{C}$ atuou significativamente na obtenção de maior porcentagem de germinação e reduzida porcentagem de sementes dormentes. Estas últimas, para as sementes de todas as plantas, foi elevada sob temperatura de $25^{\circ} \mathrm{C}$, evidenciando grande influência do fator temperatura na superação de dormência. Termos para indexação: Passiflora alata, maracujá, semente, germinação, temperatura, dormência
\end{abstract}

\section{EFFECTS OF TEMPERATURE ON EVALUATION OF PHYSIOLOGICAL QUALITY Of SEEDS ON SWEET PASSION-FRUIT (Passiflora alata Dryander)}

\begin{abstract}
With the purpose to study favorable conditions of temperature for seeds germination of sweet passion-fruit (Passiflora alata Dryander), it was used, as treatment, five plants for seeds and two germination temperatures, with no light: $25^{\circ} \mathrm{C}$ constant and alternate $20-30^{\circ} \mathrm{C}$. Mucilage of seeds, proceeding from mature fruits, completely yellow, were extracted using a mixer at low rotation. The characteristic of the evaluated seeds were: weigh, dried matter contend, water content, germination percentage (of normal seedlings), of abnormal seedlings, of dormant and died seeds. It was concluded that alternated temperature at $20-30^{\circ} \mathrm{C}$ actuated significantly to obtain higher percentage of germination and low percentage of dormant seeds. These last ones, for seeds of all plants, was elevated under temperature of $25^{\circ} \mathrm{C}$, showing great influence of temperature fact, on dormancy surpassing.
\end{abstract}

Index terms: Passiflora alata, passion fruit, seed, germination, temperature, dormancy.

A propagação comercial do maracujazeiro no Brasil é feita, predominantemente, através de sementes (Ruggiero \& Oliveira, 1998), e no que diz respeito à propagação do maracujá-doce (Passiflora alata Dryander), os estudos são escassos, sendo comum o relato do baixo percentual de germinação de suas sementes por parte de produtores, viveiristas e pesquisadores.

A temperatura influencia no total, na velocidade e na uniformidade de germinação, na velocidade de absorção de água e, portanto, nas reações bioquímicas que determinam todo o processo. Assim, a germinação só ocorrerá dentro de determinados limites de temperatura, os quais englobam uma temperatura, ou faixa de temperaturas, onde o processo ocorre com máxima eficiência. Por outro lado, um grande número de espécies apresenta uma reação germinativa favorável sob temperaturas alternadas, à semelhança do que acontece ao natural em que as temperaturas diurnas são mais altas e as noturnas menores. Algumas hipóteses tentam explicar as razões desta resposta das sementes a temperaturas alternadas, mas nenhuma é totalmente satisfatória (Carvalho \& Nakagawa, 1988).

Bewley \& Black (1982) citam que, dentre 85 espécies conhecidas e testadas, 68 responderam favoravelmente à alternância de temperatura, após a fase de embebição da semente. Os autores explicam que nem sempre fica claro quando a alternância de temperatura afeta a superação da dormência, ou se também outros aspectos, como germinação e desenvolvimento fisiológico, são envolvidos primeiramente no processo. Em algumas espécies, a alternância de temperatura parece agir, predominantemente, nos níveis de germinação e na uniformidade; mas, em muitas outras, ficam bem definidos os efeitos na superação da dormência induzida, existindo, entre elas, algumas que parecem ter uma exigência fixa para alternância de temperatura.

Akamine et al. (1956) afirmaram que há diferenças no desempenho germinativo entre as diferentes espécies de Passifloráceas. Temperaturas, constantes e alternadas, foram testadas para a germinação de sementes das espécies Passiflora edulis Sims (Pereira \& Andrade,1994), Passiflora edulis Sims f. flavicarpa (Medina et al., 1998) e Passiflora giberti ( Oliveira et al., 1998 ), obtendo-se melhores resultados para temperaturas alternadas. Na literatura consultada, praticamente inexistem estudos sobre o efeito da temperatura na germinação do Passiflora alata Dryander. Verificam-se algumas investigações a respeito do comportamento germinativo da referida espécie, estando nelas relatadas a temperatura utilizada para tal. Neste contexto, Melo et al. (1998), comparando três espécies, Passiflora edulis Sims f. flavicarpa Deg, Passiflora coccinea e Passiflora alata Ait, submetidas à temperatura de $30^{\circ} \mathrm{C}$ e fotoperíodo de $8 / 16$ horas, concluíram haver diferença altamente significativa entre elas, apontando um comportamento diferente de Passiflora alata Ait, em que as sementes não germinaram. Sanchez (1980) obteve baixa porcentagem inicial de germinação (14 e 22\%), ao pesquisar métodos para a eliminação do arilo e armazenamento em sementes da espécie Passiflora alata Ait., utilizando temperatura constante de $28^{\circ} \mathrm{C}$. Cabe salientar que, em ambas as pesquisas, os autores não mencionaram o grau de maturidade dos frutos, dos quais as sementes foram extraídas. No entanto, Ferreira (1998), para estudar a embebição e o efeito de fitorreguladores em sementes de Passifloráceas, utilizou sementes do Passiflora alata provenientes de frutos maduros e sob temperatura alternada de $20-30{ }^{\circ} \mathrm{C}$, obtendo porcentagem de germinação superior a $80 \%$ no tratamento-testemunha, o qual não diferiu em relação ao melhor tratamento.

Alguns autores mencionam a possibilidade da existência de dormência nas sementes do maracujá-doce (Oliveira et al., 1980; Sanchez, 1980; Melo et al., 1998) pela baixa ou nula germinação, obtida em suas pesquisas com essa espécie. Outros, trabalhando com essa espécie na obtenção de mudas ou porta-enxertos para estudo de resistência a doenças, mencionam existir problema com a viabilidade da semente (Oliveira et al., 1980; Ruggiero \& Oliveira, 1998).

Levando-se em consideração essas informações, o presente trabalho teve por objetivo verificar condições favoráveis de temperatura para a germinação das sementes do maracujá-doce.

Este trabalho foi conduzido no Laboratório de Análise de Sementes da FCA-UNESP, Botucatu-SP, utilizando-se de frutos provenientes de cultura comercial de segundo ano. Em cada uma das cinco plantas selecionadas, escolhram-se e marcaram-se cinco frutos

\footnotetext{
${ }^{1}$ (Trabalho 096/2004). Recebido: 03/08/2004. Aceito para publicação: 09/03/2005. Parte integrante da tese de doutorado do $1^{\circ}$ autor.

${ }^{2}$ Eng $^{\mathrm{a}}$ Agra . Prof ${ }^{\mathrm{a}}$. Doutora - FALM -, CP.261, 86360-000-Bandeirantes PR, Brasil. elisete@ffalm.br - Bolsista CAPES.

${ }^{3}$ Eng $^{\circ}$. Agr ${ }^{\circ}$. Prof ${ }^{\circ}$. Titular Aposentado/Voluntário do DPV, FCA- Botucatu- UNESP.18603-970-Botucatu-SP. secdamv@ @ca.unesp.br Bolsista CNPq.
} 
quando iniciavam a coloração amarela no ápice, os quais foram colhidos 9 dias após. Com a utilização de um liquidificador em baixa rotação, extrairam-se os arilos das sementes, seguindo-se de lavagem em água corrente. A secagem foi feita à sombra, sobre papel jornal, durante três dias, sendo após colocadas em saquinhos de papel, assim permanecendo por sete dias.

Para a determinação do peso de 100 sementes, contaram-se, manualmente e ao acaso, oito subamostras de 100 sementes, as quais foram pesadas em balança de precisão de $0.0001 \mathrm{~g}$ (Brasil, 1992). O teor de água foi avaliado pelo método da estufa a $105^{\circ} \mathrm{C} \pm 3^{\circ} \mathrm{C}$, por 24 horas, utilizando-se de quatro repetições de 50 sementes por tratamento (Brasil, 1992). O peso, em gramas, da matéria seca de 100 sementes, foi determinado, multiplicando-se por dois o peso seco de 50 sementes obtido para a determinação do teor de água. Para o teste de germinação, utilizaram-se cinco plantas como tratamento, e duas temperaturas de germinação, na ausência de luz: $25^{\circ} \mathrm{C}$ e $20-30^{\circ} \mathrm{C}$ ( 16 e 08 horas). Empregaram-se quatro amostras de 50 sementes por tratamento, previamente tratadas com Rodhiauran $0,2 \%$. A semeadura foi feita em rolo de papel toalha, e as contagens realizadas aos 7; 14; 21 e 28 dias após a semeadura. A avaliação foi feita conforme as recomendações das Regras para Análise de Sementes (Brasil, 1992), considerando-se os totais de porcentagem de germinação (plântulas normais), de plântulas anormais, de sementes dormentes e de sementes mortas, ao final do período considerado.

As porcentagens de germinação, de plântulas anormais, de sementes dormentes e de sementes mortas, foram analisadas em delineamento inteiramente ao acaso, no esquema fatorial $5 \times 2$, utilizandose de quatro repetições. As características teor de água, peso e matéria seca de 100 sementes foram analisadas em esquema inteiramente ao acaso, considerando-se tratamentos as cinco plantas e utilizando-se de oito repetições para peso de 100 sementes, e quatro repetições para as demais.

Pelas diferenças significativas observadas para os dados de peso de 100 sementes e peso da matéria seca de 100 sementes, verifica-se que havia diferença no peso das sementes entre os tratamentos (Tabela 1). Este fato pode ser atribuído à característica de planta, já que a diferença de teor de água entre as sementes, que poderiam afetar no peso de 100 sementes, foi desprezível, considerando-se a precisão do método empregado para a determinação, $105^{\circ} \mathrm{C}+3^{\circ} \mathrm{C} / 24 \mathrm{~h}$ (Brasil, 1992), apesar de terem ocorrido diferenças estatísticas.

TABELA 1 - Dados médios de teor de água (\%), de peso (g) e de peso de matéria seca (g) de 100 sementes do maracujá-doce obtidos das diferentes plantas $\left(\mathrm{P}_{1}, \mathrm{P}_{2}, \mathrm{P}_{3}, \mathrm{P}_{4}, \mathrm{P}_{5}\right)$.

\begin{tabular}{cccc}
\hline Plantas & $\begin{array}{c}\text { Peso 100 } \\
\text { sementes }\end{array}$ & $\begin{array}{c}\text { Matéria seca 100 } \\
\text { sementes }\end{array}$ & $\begin{array}{c}\text { Teor de } \\
\text { água }\end{array}$ \\
\hline $\mathrm{P}_{1}$ & $3,171 \mathrm{~d}$ & $2,903 \mathrm{c}$ & $7,9 \mathrm{~b}$ \\
$\mathrm{P}_{2}$ & $3,455 \mathrm{c}$ & $3,147 \mathrm{~b}$ & $8,2 \mathrm{a}$ \\
$\mathrm{P}_{3}$ & $3,452 \mathrm{c}$ & $3,140 \mathrm{~b}$ & $8,2 \mathrm{a}$ \\
$\mathrm{P}_{4}$ & $3,703 \mathrm{a}$ & $3,399 \mathrm{a}$ & $7,9 \mathrm{~b}$ \\
$\mathrm{P}_{5}$ & $3,493 \mathrm{~b}$ & $3,184 \mathrm{~b}$ & $8,3 \mathrm{a}$ \\
\hline DMS $(5 \%)$ & 0,03 & 0,06 & 0,24 \\
C.V. $(\%)$ & 0,64 & 0,93 & 1,37 \\
\hline
\end{tabular}

Os resultados do teste de germinação (Tabela 2) não apresentam valores referentes aos sete dias após a semeadura, pelo fato de não terem ocorrido plântulas normais nesse período. Para as características avaliadas, porcentagens de plântulas normais, de plântulas anormais, de sementes dormentes e de sementes mortas, verifica-se que ocorreu interação significativa entre temperaturas e sementes oriundas de diferentes plantas. Através dos dados obtidos, verifica-se que a temperatura alternada de 20$30^{\circ} \mathrm{C}$ atuou significativamente na obtenção de maior porcentagem de germinação (plântulas normais) de sementes de maracujá-doce, em relação à temperatura constante de $25^{\circ} \mathrm{C}$. Esses resultados diferem dos obtidos por Pereira \& Andrade (1994), para a espécie Passiflora edulis Sims, que não observaram diferença significativa para as temperaturas de $25^{\circ} \mathrm{C}, 30^{\circ} \mathrm{C}$ e temperatura alternada de $20-30^{\circ} \mathrm{C}$; para essas temperaturas, obtiveram médias de porcentagem de germinação de $41,1 \%$; 43,9\% e 46,8\%, respectivamente, não se observando diferença tão acentuada entre os valores, quanto aos obtidos para a Passiflora alata nesta pesquisa. De certa forma, o bom resultado obtido para $20-30^{\circ} \mathrm{C}$ pode justificar, pelo menos parcialmente, as baixas e nulas porcentagens de germinação obtidas por Sanchez (1980) e Melo et al. (1998), em suas investigações com a espécie Passiflora alata, já que os autores utilizaram temperaturas constantes de $28^{\circ} \mathrm{C}$ e $30^{\circ} \mathrm{C}$, respectivamente, para a realização dos testes. Por outro lado, a alta porcentagem de germinação e a baixa porcentagem de sementes dormentes obtidas neste experimento concordam com os resultados do tratamento-testemunha obtidos por Ferreira (1998) em suas investigações com Passifloráceas, para as quais utilizou temperatura alternada de $20-30^{\circ} \mathrm{C}$.

Portanto, esses resultados reforçam a importância da temperatura alternada como forma de superação da dormência, como relataram Bewley \& Black (1982)e Carvalho \& Nakagawa(1988).

O comportamento entre as sementes das diferentes plantas, para as porcentagens de plântulas normais obtidas à temperatura constante de $25^{\circ} \mathrm{C}$, apresentou valores sempre baixos e não-significativos. Já para a faixa de temperatura de $20-30^{\circ} \mathrm{C}$, de forma geral, o comportamento entre as sementes das plantas variou significativamente, apresentando aumento contínuo de plântulas normais no decorrer das contagens realizadas, aumento este mais acentuado aos 21 dias da semeadura. Por outro lado, observou-se pequeno e constante acréscimo aos valores obtidos a $25^{\circ} \mathrm{C}$, sendo que a planta 4 se manteve com valor nulo.

Pelos resultados obtidos ao final do teste de germinação (Tabela 2), observa-se que, para todas as plantas, a porcentagem de sementes dormentes foi elevada sob temperatura de $25^{\circ} \mathrm{C}$, e reduzida a $20-30^{\circ} \mathrm{C}$, evidenciando grande influência do fator temperatura na superação de dormência. Isto demonstra que as sementes do Passiflora alata não necessitam, obrigatoriamente, de tratamentos pré-germinativos como sugeriu Morley-Bunker (1974). Por outro lado, é interessante observar que, nos ensaios em condições de laboratório e viveiro, realizados por Sanchez (1980) para superação de dormência com diversos tratamentos, o referido autor obteve para as testemunhas, nessas condições, $5 \%$ e $18 \%$, respectivamente. É bastante provável que a maior porcentagem conseguida no viveiro seja decorrente da alternância de temperatura dia-noite atuante, enquanto no laboratório as sementes foram mantidas à temperatura constante de $28^{\circ} \mathrm{C}$. Ainda assim, os baixos valores obtidos pelas testemunhas no trabalho citado poderiam estar associados a algum outro problema existente nas sementes, além da dormência. Outro aspecto importante a ser observado no presente trabalho é que há uma diferença marcante entre as plantas, quanto ao nível de dormência apresentada por suas sementes, pois verifica-se que mesmo a $20-30^{\circ} \mathrm{C}$ têm-se plantas com percentual considerável de sementes dormentes (Tabela 2).

No final dos testes, as plântulas anormais, com exceção das sementes da planta 1, apresentaram comportamento diferente das sementes dormentes, pois mostraram valores baixos e não-significativos para ambas as temperaturas. Além disso, percebe-se uma similaridade de comportamento, quando se comparam os valores obtidos em cada planta, nas temperaturas utilizadas, indicando a possibilidade de existir, aí, uma tendência genética, já que as sementes das plantas que tiveram menores valores de plantas anormais a $25^{\circ} \mathrm{C}$, também os tiveram a $20-30^{\circ} \mathrm{C}$.

É interessante observar que a planta que apresentou sementes com maior porcentagem de germinação a $20-30^{\circ} \mathrm{C}$, mostrou $100 \%$ de sementes dormentes a $25^{\circ} \mathrm{C}$. Cabe aqui relembrar a experiência de Melo et al. (1998), que não obtiveram germinação de sementes do Passiflora alata, sob condições de temperatura constante de $30^{\circ} \mathrm{C}$.

De modo geral, as sementes mortas apresentaram baixos percentuais, não diferindo entre plantas nem entre temperaturas, mostrando que estas não interferiram nos demais resultados obtidos.

Pelos resultados obtidos, conclui-se que a temperatura alternada de $20-30^{\circ} \mathrm{C}$ possibilitou maior porcentagem de germinação de sementes de maracujá-doce, por ter favorecido a superação da dormência. 
TABELA 2 - Dados médios de porcentagens de plântulas normais (14; 21 e 28 dias de semeadura), plântulas anormais, sementes dormentes e mortas obtidos no teste de germinação em função das variações de temperatura $\left(25^{\circ} \mathrm{C}\right.$ e $\left.20-30^{\circ} \mathrm{C}\right)$ e de plantas $\left(\mathrm{P}_{1}, \mathrm{P}_{2}, \mathrm{P}_{3}, \mathrm{P}_{4}, \mathrm{P}_{5}\right)$.

\begin{tabular}{|c|c|c|c|c|c|c|c|c|c|c|c|c|}
\hline \multirow{2}{*}{\multicolumn{3}{|c|}{$\begin{array}{c}14 \text { dias } \\
\text { Normais }\end{array}$}} & \multirow{2}{*}{\multicolumn{2}{|c|}{$\begin{array}{c}21 \text { dias } \\
\text { Normais }\end{array}$}} & \multicolumn{8}{|c|}{28 dias } \\
\hline & & & & & \multicolumn{2}{|c|}{ Normais } & \multicolumn{2}{|c|}{ Anormais } & \multicolumn{2}{|c|}{ Dormentes } & \multicolumn{2}{|c|}{ Mortas } \\
\hline & $25^{\circ} \mathrm{C}$ & $20-30^{\circ} \mathrm{C}$ & $25^{\circ} \mathrm{C}$ & $20-30^{\circ} \mathrm{C}$ & $25^{\circ} \mathrm{C}$ & $20-30^{\circ} \mathrm{C}$ & $25^{\circ} \mathrm{C}$ & $20-30^{\circ} \mathrm{C}$ & $25^{\circ} \mathrm{C}$ & $20-30^{\circ} \mathrm{C}$ & $25^{\circ} \mathrm{C}$ & $20-30^{\circ} \mathrm{C}$ \\
\hline $\mathrm{P}_{1}$ & 2,0 a B & $19,0 \mathrm{~b} \quad \mathrm{~A}$ & 2,5 a $B$ & 71,5 ab A & 5,0 a $\mathrm{B}$ & 77,5 bc $A$ & $1,5 \mathrm{ab} B$ & $5,0 \mathrm{ab} A$ & $92,5 \mathrm{ab} \mathrm{A}$ & 17,0 bc B & 1,0 a $\mathrm{A}$ & 0,5 a $A$ \\
\hline $\mathrm{P}_{2}$ & 1,5 a $\mathrm{B}$ & $11,0 \mathrm{bc} \mathrm{A}$ & 3,0 a $\mathrm{B}$ & $64,0 \quad \mathrm{~b} \quad \mathrm{~A}$ & 3,5 a $\mathrm{B}$ & $72,0 \quad \mathrm{c} \quad \mathrm{A}$ & 5,5 a $\mathrm{A}$ & $4,0 \mathrm{ab} \mathrm{A}$ & $89,5 \mathrm{ab} \mathrm{A}$ & 24,0 ab B & 1,5 a $\mathrm{A}$ & 0,0 a $B$ \\
\hline $\mathrm{P}_{3}$ & 1,5 a B & 53,0 a $\mathrm{A}$ & 2,5 a $\mathrm{B}$ & 81,0 a $\mathrm{A}$ & 4,0 a $\mathrm{B}$ & 85,5 ab A & $0,5 \mathrm{~b} \quad \mathrm{~A}$ & $1,0 \mathrm{~b} \quad \mathrm{~A}$ & $95,5 \mathrm{ab} A$ & $13,5 \mathrm{bc} \mathrm{B}$ & 0,0 a $\mathrm{A}$ & 0,0 a $\mathrm{A}$ \\
\hline $\mathrm{P}_{4}$ & 0,0 a $\mathrm{A}$ & $5,0 \quad \mathrm{c} \quad \mathrm{A}$ & 0,0 a $\mathrm{B}$ & 73,5 ab A & 0,0 a $\mathrm{B}$ & 91,0 a $\mathrm{A}$ & $0,0 \mathrm{~b} \quad \mathrm{~A}$ & $1,0 \mathrm{~b} \quad \mathrm{~A}$ & $100,0 \mathrm{a} \quad \mathrm{A}$ & $8,0 \mathrm{C} \quad \mathrm{B}$ & 0,0 a $\mathrm{A}$ & 0,0 a $\mathrm{A}$ \\
\hline $\mathrm{P}_{5}$ & 2,5 a A & $2,5 \quad \mathrm{c} \quad \mathrm{A}$ & 6,0 a $\mathrm{B}$ & 36,5 c A & 8,5 a $\mathrm{B}$ & $58,0 \quad \mathrm{~d} \quad \mathrm{~A}$ & 6,0 a $A$ & 7,0 a $\mathrm{A}$ & $84,5 \mathrm{~b} \quad \mathrm{~A}$ & $33,5 \mathrm{~A}$ B & 1,0 a $\mathrm{A}$ & 1,5 a $\mathrm{A}$ \\
\hline \multicolumn{2}{|c|}{$\begin{array}{l}\text { D.M.S. 5\% } \\
\text { (temperatura) }\end{array}$} & 6,61 & \multicolumn{2}{|c|}{7,79} & \multicolumn{2}{|r|}{8,43} & \multicolumn{2}{|c|}{3,26} & \multicolumn{2}{|c|}{8,27} & \multicolumn{2}{|c|}{1,32} \\
\hline \multicolumn{2}{|c|}{$\begin{array}{l}\text { D.M.S. 5\% } \\
\text { (plantas) }\end{array}$} & 9,38 & \multicolumn{2}{|c|}{11,05} & \multicolumn{2}{|c|}{11,95} & \multicolumn{2}{|c|}{4,63} & \multicolumn{2}{|c|}{11,73} & \multicolumn{2}{|c|}{1,87} \\
\hline \multicolumn{2}{|c|}{ C.V. (\%) } & 46,69 & \multicolumn{2}{|c|}{15,83} & \multicolumn{2}{|c|}{14,40} & \multicolumn{2}{|c|}{71,69} & \multicolumn{2}{|c|}{10,25} & \multicolumn{2}{|c|}{165,98} \\
\hline
\end{tabular}

Médias seguidas de mesma letra minúscula na vertical e maiúsculas na horizontal, em cada avaliação, não diferem entre si, pelo teste de Tukey, a nível de $5 \%$ de probabilidade.

\section{REFERÊNCIAS}

AKAMINE, E.K.; BEAUMONT, J.H.; BOWERS, F.A.I.; HAMILTON, R.A.; NISHIDA, T.; SHAW, T.N. Passion fruit culture in Hawaii. Hawaii: University of Hawaii, 1956. 35p. (Extension Circular, 345).

BEWLEY, S.D.; BLACK, M. Physiology and biochemistry of seeds. New York: Springer-Verlag, 1982. 375p.

BRASIL. Ministério da Agricultura. Regras para análise de sementes. Brasília, 1992.p.365.

CARVALHO, N.M.; NAKAGAWA, J. Sementes: ciência, tecnologia e produção. 3.ed. Campinas: Fundação Cargill, 1988. 424p.

FERREIRA, G. Estudo da embebição e do efeito de fitorreguladores na germinação de sementes de Passifloráceas. 1998. 145f. Tese (Doutorado em Agronomia) - Faculdade de Ciências Agronômicas, Universidade Estadual Paulista, Botucatu, 1998.

MEDINA, P.F.; MAEDA, J.A.; MELETTI, L.M.M. Condições de germinação de semente de maracujá (Passiflora edulis f. flavicarpa). In:CONGRESSOBRASILEIRODEFRUTICULTURA, 15., 1998. Poços de Caldas. Resumos... Lavras:UFLA, 1998. p.566.

MELO,A.L.; PENÁRIO, R.; SADER, R.; OLIVEIRA, J.C. Comportamento germinativo de espécies de maracujá. Jaboticabal: Faculdade de Ciências Agrárias e Veterinárias, UNESP, 1998. 8p.

MORLEY-BUNKER, M.J.S. Some aspects of seed dormancy with reference to Passiflora spp. and other tropical and subtropical crops. London: University of London, 1974. 43p.
OLIVEIRA, J.C.; SALOMÃO, T.A.; RUGGIERO C.; ROSSINI,A.C. Observações sobre o cultivo de Passiflora alata AIT. (maracujá Guaçu). Revista Brasileira de Fruticultura, Jaboticabal, v.2, n.1, p.59-63, 1980.

OLIVEIRA, M.A.; DUARTE FILHO, J.; VASCONCELLOS, M.A.S.; CARVALHO, C.M.; LEONEL, S. Germinação de sementes de Passiflora giberti Brow sob temperatura controlada. In: CONGRESSO BRASILEIRODEFRUTICULTURA, 15., 1998, Poços de Caldas. Resumos... Lavras:UFLA, 1998. p.557

PEREIRA, T.S. ANDRADE, A.C.S. Germinação de Psidium guajava L. e Passiflora edulis Sims - Efeito da temperatura, substrato e morfologia do desenvolvimento pós-seminal. Revista Brasileira de Sementes, Brasília, v.16, n.1, p.58-62, 1994.

RUGGIERO, C.; OLIVEIRA, J.C. Enxertia do maracujazeiro. In: RUGGIERO, C. (Ed.). Maracujá: do plantio à colheita. Jaboticabal: Fundação de estudos e Pesquisas em Agronomia, Medicina Veterinária e Zootecnia, Universidade Estadual Paulista, 1998. p.7092.

SANCHEZ, S.V. Influência de tipos de degomagem e armazenamento sobre a germinação de sementes e estudo sobre a quebra de dormência de maracujá-doce (Passiflora alata Ait). Jaboticabal: Faculdade de Ciências Agrárias e Veterinárias, Universidade Estadual Paulista, 1980. 21f. (Monografia). 